\title{
Article \\ Biochemical Profile and Antimicrobial Activity of an Herbal-Based Formula and Its Potential Application in Cosmetic Industry
}

\author{
Alice Grigore ${ }^{1, *(D)}$, Lucia Camelia Pirvu ${ }^{1} \mathbb{D}$, Ionica Bejanaru ${ }^{1}$, Georgeta Neagu ${ }^{1}$, Camelia Filofteia Diguta ${ }^{2,3}$, \\ Luciana Glava ${ }^{4}$, Carmen Ionita ${ }^{5}$ and Florentina Matei ${ }^{2,3}$
}

1 National Institute for Chemical-Pharmaceutical Research and Development-ICCF Bucharest, Calea Vitan, no. 112, 3rd District, 031299 Bucharest, Romania; lucia.pirvu@yahoo.com (L.C.P.); ionicabejanaru@yahoo.com (I.B.); georgetaneagu2008@gmail.com (G.N.)

2 Center of Microbial Biotehnologies "Biotehgen", 59 Marasti Blvd., 1st District, 060021 Bucharest, Romania; camifilo@yahoo.com (C.F.D.); flore_radoi@hotmail.com (F.M.)

3 Faculty of Biotechnology, University of Agronomic Sciences and Veterinary Medicine of Bucharest, 59 Marasti Blvd., 1st District, 011464 Bucharest, Romania

4 SC Dacia Plant SRL, Harmanului Str., Bod, 507015 Brasov, Romania; luciana.glava@daciaplant.ro

5 Faculty of Veterinary Medicine, University of Agronomic Sciences and Veterinary Medicine of Bucharest, 59 Marasti Blvd., 1st District, 050097 Bucharest, Romania; ionitacarmen757@gmail.com

* Correspondence: alicearmatu@yahoo.com

check for updates

Citation: Grigore, A.; Pirvu, L.C.; Bejanaru, I.; Neagu, G.; Diguta, C.F.; Glava, L.; Ionita, C.; Matei, F.

Biochemical Profile and

Antimicrobial Activity of an Herbal-Based Formula and Its Potential Application in Cosmetic Industry. Appl. Microbiol. 2022, 2, 227-236. https://doi.org/10.3390/ applmicrobiol2010016

Academic Editors: Filomena Nazzaro, Vincenzo De Feo and Raffaele Coppola

Received: 26 January 2022

Accepted: 25 February 2022

Published: 28 February 2022

Publisher's Note: MDPI stays neutral with regard to jurisdictional claims in published maps and institutional affiliations.

Copyright: (C) 2022 by the authors. Licensee MDPI, Basel, Switzerland. This article is an open access article distributed under the terms and conditions of the Creative Commons Attribution (CC BY) license (https:// creativecommons.org/licenses/by/ $4.0 /)$

\begin{abstract}
Microbial infections, and especially microbial resistance, are critical and actual problems that require targeted and efficient therapeutic intervention. Natural-based solutions are a viable alternative, at least for complementary therapy, due to few or no side effects and high safety and efficacy levels. The aim of this study was to demonstrate the potential use of a patented formula based on Achillea millefolium, Origanum vulgare, and Lychnis coronaria species as an antibacterial ingredient, mainly for skin and mucosal infections, in order to support its pharmaco-cosmetic application. The chemical composition of the formula was analyzed by HPLC and spectrophotometric methods. Furthermore, antioxidant and antimicrobial activity were evaluated. To determine the formula's safety for topical application, it was used on a reconstructed human epidermal model. The formula showed inhibitory activity on both Gram-positive and Gram-negative bacteria, respectively, moderate inhibition on B. cereus, Kocuria kristinae, P. aeurginosa, S. enterica Typhimurium, methicillin-resistant and methicillin-sensible $S$. aureus, as well as high inhibition on S. epidermidis, Serratia marescens, and Streptococcus pyogenes. The developed product was biochemically characterized for its content in polyphenols, triterpenes, and polyphenol carboxylic acids. The formula was proven to have a nonirritant effect on the human epidermis and important antioxidant activity.
\end{abstract}

Keywords: Achillea millefolium; Origanum vulgare; Lychnis coronaria

\section{Introduction}

With the increasing prevalence of infectious diseases and the ability of microbials to develop resistance, the development of innovative routes to fight infections has become imperative.

Before the discovery of antibiotics, microbial infections were treated with herbal medicines or cauterization [1]. Natural compounds or extracts can be a valid choice to support the efficiency of allopathic medication, either as a monotherapy or as an adjuvant [2]. These phytochemicals can use several strategies; they can enhance antimicrobial drug activity, they can inhibit bacterial enzymes, or they can act as efflux-pump inhibitors. Many phytochemicals in combination with existing drugs were found to act as resistance modifying agents, and proper combinations may rescue the efficacy of important, lifesaving 
antimicrobial agents [3]. Moreover, many antimicrobial herbal medicines possess simultaneous antibacterial, antifungal, antiprotozoal, and/or antiviral properties, but they also have immunostimulatory properties, which are particularity valuable in immunocompromised patients [4].

Herbal-based antimicrobial formulations are a proven alternative to synthetic compounds, with high applicability in various areas: food [5]; dermatology-for skin and soft tissue infections [6]; dentistry [7,8]; cosmetics [9]; and medicine [3]; Kolodziej, [10].

The Achillea genus comprises more than 100 species, many of them used in traditional medicine for their antispastic, anti-inflammatory, and cicatrizing effects [11]. The most widespread species, Achillea millefolium L. (yarrow or milfoil), has been listed among the most commonly used plant species in both folk and conventional medicine for over 3000 years [12]. Its therapeutic effects are correlated to the rich content of various secondary metabolites, such as flavonoids, phenolic acids, terpenes, guaianolides, phytosterols, fatty acids, and organic acids [13]. As regards skin infections, it was found that A. millefolium extracts are the most potent antimicrobial ingredients, able to inhibit microorganisms, such as $S$. aureus and P. aeruginosa, which are usually resistant to plant extracts [14].

The genus Lychnis (syn. Silene), belonging to the tribe Sileneae of the family Caryophyllaceae, comprises 25-30 species growing in Northern and Eastern Europe and also in Asia, and includes weeds, ornamental plants, and species of medicinal value. Since ancient times, this plant was used to treat diarrhea, lung and liver ailments, leprosy, and beriberi [15]. Modern studies highlighted its antimicrobial effect; methanol and ethanol extracts are capable of inhibiting the growth of both Gram-negative and Gram-positive bacteria, such as Klebsiella oxytoca, Escherichia coli, Proteus rettgeri, Citrobacter freundii, Pseudomonas aeruginosa, Alcaligenes faecalis, Enterobacter hormaechei, Pantoea agglomerans, Bacillus cereus, Staphylococcus epidermidis, Micrococcus luteus, and K. aerogenes. The chloroform extract has a wider range of bactericidal activity, also inhibiting the growth of $S$. aureus, Acinetobacter sp., and S. saprophyticus strains, probably due to the presence of phytoecdysteroids (Mamadalieva 2012).

Other studies have confirmed that the ethanol, methanol, ethyl acetate, and propanol extracts of $S$. coronaria leaves and branches exhibit antibacterial activity against $S$. aureus, while the propanol extract is also active against $A$. hydrophila [16].

Different types of Origanum extracts are active against E. coli and B. subtilis [17], as well as Salmonella serotypes Salmonella gallinarum, Salmonella enteritidis, and S. typhimurium [18].

Although the literature data confirmed the benefits of using each one of these three herbal species in the treatment of various microbial diseases, this study aimed to demonstrate the potential use of a patented formula based on a mixture of them as an antibacterial ingredient, mainly for skin and mucosal infections, in order to support its pharmacocosmetic application. The research conducted on the formula containing Achillea millefolium, Origanum vulgare, and Lychnis coronaria extracts included an analytical characterization of the main compounds and a screening of the antimicrobial and antioxidant effects. In addition, to support its safety for topical application, the developed formula was tested for any irritant potential on a reconstructed human epidermal model.

\section{Materials and Methods}

\subsection{Preparation of the Bioactive Solution}

The solution was prepared according to patent no. RO118996/2004 with a slight modification.

Achillea millefolium, Origanum vulgare, and Lychnis coronaria L. were provided by S.C. Dacia Plant S.R.L., Bod, Romania which cultivates these species under ecological conditions. The raw material was dried and ground as a fine powder. Voucher specimens (AM22/2020, OV16/2020, and LC6/2020, respectively) were deposited at the manufacturer.

Briefly, a mixture of Lychnis coronaria, Origanum vulgare, and Achillea millefolium (5:3:2 $w / w / w /$ ) raw materials was homogenized with 30\% ethyl alcohol (in a ratio of vegetable raw material/solvent of $1: 5 \mathrm{~m} / \mathrm{v}$ ) and left to soak at room temperature for 7 days with occasional stirring. After filtration, a reddish-brown solution was obtained and further 
concentrated at reduced pressure and $60^{\circ} \mathrm{C}$, up to $5: 1 \mathrm{v} / \mathrm{v}$ compared to the initial solution. About $20 \mathrm{~mL}$ of concentrated ethyl alcohol was added to this solution and left in a refrigerator for 4 days, then filtered in vacuo to obtain a final, clear, reddish-brown solution. To this was added glycerin ( $70 \%$ of the total volume) to stabilize the solution.

\subsection{Biochemical Profile}

2.2.1. Spectrophotometric Analysis of Phenolic Compounds

Quantification of the total phenolic compounds expressed in gallic acid was performed by a Folin-Ciocalteu colorimetric method, which is based on the formation of colored complexes with maximum absorption in VIS at $\lambda=750 \mathrm{~nm}$.

\subsubsection{Spectrophotometric Analysis of Triterpenic Acids}

The dosing of triterpene compounds was performed by a UV-absorption spectrophotometric method. The principle of the method consists in the dehydration of triterpenic acids in the presence of concentrated sulfuric acid at a temperature of $70{ }^{\circ} \mathrm{C}$ for $2 \mathrm{~h}$, time necessary to complete the reaction when 2 absorption peaks appear in the product spectrum at $\lambda=302-320 \mathrm{~nm}$ and at $\lambda=405-410 \mathrm{~nm}$.

\subsubsection{Quantitative Analysis by High-Performance Liquid Chromatography (HPLC)}

The optimal conditions for analysis were determined using specific standards for compounds of interest. Quantitative HPLC analysis of the main polyphenolic components was performed on a HPLC SHIMADZU, with a DAD detector; a Kromasil C18 column $(100 \mathrm{~mm} \times 4.6 \mathrm{~mm})$ for polyphenol carboxylic acids at $25^{\circ} \mathrm{C}$, using a gradient elution. Separation of polyphenols was performed using water acidified with formic acid $1 \%$ and methanol acidified with formic acid 1\%, respectively, as mobile phase at an initial flow rate of $0.1 \mathrm{~mL} / \mathrm{min}$, with an injection of $15 \mu \mathrm{L}$. All reference substances (chlorogenic, rosmarinic, caffeic, and gallic acids were purchased from Sigma-Aldrich (Darmstadt, Germany).

\subsubsection{Antioxidant Activity}

The free radical scavenging activities of the product were determined according to a method adapted by Brand-Williams et al. [19], using the stable free radical, diphenylpicryl-hydrazyl (DPPH). Briefly, $2 \mathrm{~mL}$ of $100 \mu \mathrm{M}$ ethanolic solution of DPPH was mixed with $1 \mathrm{~mL}$ plant formula, shaken vigorously, and further incubated for $30 \mathrm{~min}$ at room temperature in a dark place. The change in color from deep violet to light yellow was measured at $515 \mathrm{~nm}\left(\mathrm{~A}_{\text {sample }}\right)$, and the percentage of the radical scavenging activity (RSA) was calculated by using the following equation: $\%$ RSA $=\left(1-\left[\mathrm{A}_{\text {sample }} / \mathrm{A}_{\text {control } \mathrm{t}=0}\right]\right) / 100$. As a negative control, a DPPH $100 \mu \mathrm{M}$ solution in $80 \%$ ethanol was used, while as a positive control, a $0.02 \%$ L-ascorbic acid was used. The results were expressed as means for three measurements.

\subsection{Pharmacologic Activity}

\subsubsection{Irritant Potential}

To assess the skin irritation potential of the formula, a reconstructed human epidermal model, EpiDerm EPI-200 (MatTek Corporation, Ashland, MA, USA) consisting of normal, multi-layered, human-derived epidermal keratinocytes was used. The procedure was followed in accordance with the manufacturer's instructions. Cell viability was measured by the MTT reduction assay. As a positive control, 5\% sodium dodecyl sulfate (SDS) was used, while as a negative control, Dulbecco's phosphate-buffered saline (DPBS) was used. Relative cell viability was calculated for each tissue as a percentage of the mean of the negative control tissues. In accordance with UN GHS, the test substance was considered to be a nonirritant to skin if the tissue viability after exposure and post-treatment incubation were greater than $50 \%$. 


\subsubsection{Antimicrobial Effect}

\section{Tested Microorganisms}

For the antagonistic test, we took into account both Gram-positive and Gram-negative pathogenic bacteria, as well as some fungi showing pathogenic potential in humans and animals, such as Candida spp. and Aspergillus spp., as seen in Table 1.

Table 1. Pathogenic microorganisms used in the antagonistic tests.

\begin{tabular}{|c|c|c|}
\hline No. & Microorganisms & Origin \\
\hline \multicolumn{3}{|c|}{ Bacterii } \\
\hline 1. & Bacillus cereus $\mathrm{CP} 1$ & UASMVB collection \\
\hline 2. & Kocuria kristinae & UASMVB collection \\
\hline 3. & Escherichia coli ATCC * 8739 & ATCC \\
\hline 4. & Listeria ivanovii ATCC 19119 & ATCC \\
\hline 5. & Listeria monocytogens ATCC 7644 & ATCC \\
\hline 6. & Proteus vulgarius ATCC 13315 & ATCC \\
\hline 7. & Pseudomonas aeruginosa ATCC 9027 & ATCC \\
\hline 8. & Salmonella enterica Typhimurium ATCC 14028 & ATCC \\
\hline 9. & Staphylococcus aureus ATCC6538 & ATCC \\
\hline 10. & S. aureus ATCC 33592 MRSA ** & ATCC \\
\hline 11. & S. epidermidis ATCC12228 & ATCC \\
\hline 12. & S. epidermidis ATCC 51625 MRSE ** & ATCC \\
\hline 13. & Serratia marescens ATCC 14756 & ATCC \\
\hline 14. & Streptococcus pyogens ATCC 19615 & ATCC \\
\hline 15. & Enterococcus faecalis ATCC 29212 & ATCC \\
\hline \multicolumn{3}{|c|}{ Fungi } \\
\hline 16. & Candida albicans ATCC 10231 & ATCC \\
\hline 17. & C. parapsilosis ATCC20019 & ATCC \\
\hline 18. & C. glabrata ATCC 2001 & ATCC \\
\hline 19. & C. tropicalis ATCC 44508 & ATCC \\
\hline 20. & C. guilliermondii MI 40 & UASMVB collection \\
\hline 21. & C. krusei 2016 MI 41 & UASMVB collection \\
\hline 22. & Aspergillus carbonarius & UASMVB collection \\
\hline 23. & Aspergillus niger & UASMVB collection \\
\hline 24. & Aspergillus flavus & UASMVB collection \\
\hline
\end{tabular}

Legend: * ATCC-American Type Culture Collection; ${ }^{* *}$ MRSA and MRSE-methicillin-resistant.

Testing the Inhibitory Activity on Pathogenic Microorganisms

For assessing the antagonistic activity of the product against pathogenic microorganisms, a slightly modified method of the disk-diffusion assay (Kirby-Bauer test) was used. The medium used for growing pathogenic bacteria was nutrient-agar, while for the yeast and molds, PDA (potato-dextrose-agar) (VWR, Leicestershire, UK). A double-layer media was prepared; the bottom layer contained $2 \%$ agar, while the upper layer $1 \%$ agar. The pathogenic microorganisms were incorporated in the second layer of the media, while a quantity of $100 \mu \mathrm{L}$ of tincture was poured in small holes made in the first layer of the medium. After $48 \mathrm{~h}$ of incubation at $37^{\circ} \mathrm{C}$ for bacteria and $28^{\circ} \mathrm{C}$ for fungi, the inhibition 
zones were measured. All experiments were performed in triplicate. A solution of 30\% methanol $(v / v)$ was used as a control.

The results were expressed as the mean \pm standard deviation (SD), and all investigations were done in triplicate. The differences were analyzed by one-way analysis of variance (ANOVA). The significance level was set as follows: significant, $p \leq 0.05$; very significant, $p \leq 0.01$; and highly significant, $p \leq 0.001$.

\section{Results}

A patented formula made of Achillea millefolium, Origanum vulgare, and Lychnis coronaria (Patent RO118996/2004), was tested for its pharmaco-cosmetic potential. In this respect, the developed product was characterized for its biochemical composition and tested for its irritant activity and inhibitory activity against different human- and animalpathogenic microorganisms.

\subsection{Biochemical Profile}

\subsubsection{Total Polyphenols and Triterpenes}

Phenolic compounds are a large and representative class for the Origanum and Achillea genera, and triterpenes are mainly found in Lychnis. The chemical content of the formula is presented in comparison to the raw material (see Table 2). It can be noted that Origanum has the highest polyphenol content.

Table 2. Spectrophotometric analysis of phenolic and triterpene compounds.

\begin{tabular}{ccc}
\hline Sample & $\begin{array}{c}\text { Total Polyphenols Expressed } \\
\text { as Gallic Acid (\%) }\end{array}$ & $\begin{array}{c}\text { Total Triterpenes } \\
\text { Expressed as } \\
\text { Ursolic Acid (\%) }\end{array}$ \\
\hline Raw material Origanum vulgare & 6.070 & 1.053 \\
\hline Raw material Lychnis coronaria & 0.540 & 2.792 \\
\hline Raw material Achillea millefolium & 1.098 & 1.051 \\
\hline Herbal formula & 0.916 & 0.478 \\
\hline
\end{tabular}

\subsubsection{Polyphenol Carboxylic Acids}

The main detected polyphenol carboxylic acids were chlorogenic acid, caffeic acid, rosmarinic acid, and gallic acid; their content in the formula is shown in Table 3.

Table 3. Quantitative analysis of the formula by high-performance liquid chromatography (HPLC).

\begin{tabular}{cc}
\hline Polyphenol Carboxylic Acid Content (HPLC) & $\mathbf{m g} \mathbf{1 0 0 ~} \mathbf{~ L :}$ \\
\hline -Chlorogenic acid: & 10.58 \\
-Caffeic acid: & 11.66 \\
-Rosmarinic acid: & 19.33 \\
-Gallic acid: & 0.68 \\
Total: & 42.26 \\
\hline
\end{tabular}

The three genera used in this formula are rich in phenolic compounds, and some studies have linked this content to antimicrobial efficiency. O. vulgare is an important source of polyphenolic compounds as was suggested by Oniga et al., [20] who found that the representative phenolic compound is rosmarinic acid $(12.83 \mathrm{mg} / \mathrm{g}$ ), followed by chlorogenic acid $(2.10 \mathrm{mg} / \mathrm{g})$, while gentisic and $p$-coumaric acids are present in trace amounts [20].

In another Achillea species, A. moschata, it was shown that only the most polar fraction displayed antimicrobial activity, probably due to phenolics such as apigenin, centaureidin, and nevadensin [21]. The $A$. schurii extract also revealed a remarkable inhibitory activity against Listeria monocytogenes, Staphylococcus aureus, and Salmonella typhimurium which 
correlated with high phenolic content [22]. Several phenolic acids were also identified in L. flos-cuculi extracts: 4-hydroxybenzoic acid, caffeic acid, ferulic acid, vanillic acid, $p$-coumaric acid, and protocatechuic acid [23].

\subsubsection{Antioxidant Activity}

One of the methods for antioxidant potential assessment of a compound/preparation is DPPH assay. The DPPH radical is a stable, organic, free radical with an absorption maximum band around 515-528 $\mathrm{nm}$, which can be reduced by antioxidant samples to a yellow-colored compound, diphenyl picrylhydrazine, the extent of the reaction depending on the hydrogen-donating ability of the antioxidants (Brand-Williams et al., 1995). Lascorbic acid was used as positive control due to its capacity to reduce and decolorize 1,1-diphenyl-2-picrylhydrazine, reaching a maximum inhibition of $97.92 \pm 0.62 \%$. In revanche, the plant extract formula reached a maximum inhibition activity of $83.24 \pm 1.86 \%$, representing $85 \%$ of the inhibitory activity of the L-ascorbic acid. The antioxidant activity of A. millefolium was reported previously as different ethanolic, methanolic, or aqueous extracts; in ethanolic extract, the inhibitory activity at a concentration of $30 \mu \mathrm{g} / \mathrm{mL}$ extract was above $83.23 \%$ [24], which is close to the value obtained for our formula.

\subsection{Pharmacologic Activity}

\subsubsection{Irritant Potential}

A reconstructed human epidermal model is widely used to prove the safety of various products (chemicals, cosmetics, raw materials, etc.) in terms of skin corrosion, irritation, and penetration (Faller et al., 2002). According to the obtained data (Table 4), the formula was proven to be nonirritant for the human epidermis.

Table 4. Cell viability levels expressed as mean \pm SEM, based on reconstructed human skin * $p<0.05$ significantly different compared to untreated group.

\begin{tabular}{ccccc}
\hline Sample * & Average OD & Stdev & $\begin{array}{c}\text { Relative } \\
\text { Viability }\end{array}$ & Conclusion \\
\hline Positive control (DPBS) & $1.1643 \pm 0.125$ & - & & \\
\hline Negative control (SDS) & $0.0875 \pm 0.240$ & 0.0016 & 8.86 & \\
\hline Formula & $1.0906^{*} \pm 0.135$ & 0.7890 & 110.88 & Nonirritant (NI) \\
\hline
\end{tabular}

\subsubsection{Antimicrobial Effect}

The formula based on Achillea millefolium, Origanum vulgare, and Lychnis coronaria was tested in triplicate for their antagonistic effects against several pathogenic bacteria, as well as against Candida spp. and Aspergillus spp., which are frequent fungi in animal and human infections.

Generally, the formula exhibits moderate to high inhibitory activity against several pathogenic bacteria, as seen in Table 5. For instance, moderate inhibitory activity was registered in the case of Gram-positive bacteria, such as B. cereus, K. kristinae, and methicillinresistant and methicillin-sensible $S$. aureus, as well as on Gram-negative bacteria, such as $P$. aeurginosa and S. enterica thyphimurium. High inhibitory activity was noticed against Gram-positive species, such as Staphylococcus epidermidis and Streptococcus pyogenes, and on Gram-negative bacteria, such as $S$. marescens. Low inhibitory activity was limited to species like E. coli, Listeria ivanovii, and Enterococcus faecalis, while no inhibition was shown in the case of Listeria monocytogenes and Proteus vulgaris. Some relevant inhibitory activity can be observed in Figure 1. 
Table 5. Antibacterial activity of the formula based on A. millefolium, O. vulgare, and L. coronaria.

\begin{tabular}{|c|c|c|c|}
\hline Nr. crt. & Microorganism & Inhibition Diameter (mm) & Antibacterial Activity \\
\hline 1. & Bacillus cereus $\mathrm{CP} 1$ & $17 \pm 0.25$ & ++ \\
\hline 2. & Kocuria kristinae & $18 \pm 0.15$ & ++ \\
\hline 3. & Escherichia coli ATCC 8739 & $7 \pm 1.2$ & + \\
\hline 4. & Listeria ivanovii ATCC 19119 & $4 \pm 1.4$ & + \\
\hline 5. & Listeria monocytogens ATCC 7644 & - & - \\
\hline 6. & Proteus vulgarius ATCC 13315 & - & - \\
\hline 7. & Pseudomonas aeruginosa ATCC 9027 & $12 \pm 0.25$ & ++ \\
\hline 8. & Salmonella enterica Typhimurium ATCC 14028 & $16 \pm 0.34$ & ++ \\
\hline 9. & Staphylococcus aureus ATCC6538 & $18 \pm 0.25$ & ++ \\
\hline 10. & S. aureus ATCC33592 MRSA & $19.7 \pm 0.14$ & ++ \\
\hline 11. & S. epidermidis ATCC 51625 MRSE & $21 \pm 0.15$ & +++ \\
\hline 12. & S. epidermidis ATCC12228 & $20 \pm 0.17$ & ++ \\
\hline 13. & Serratia marescens ATCC 14756 & $28 \pm 0.25$ & +++ \\
\hline 14. & Streptococcus pyogens ATCC 19615 & $31 \pm 0.35$ & +++ \\
\hline 15. & Enterococcus faecalis ATCC 29212 & $5 \pm 0.10$ & + \\
\hline
\end{tabular}

Legend: - = no inhibitory activity; + = 1-10 $\mathrm{mm} ;++=11-20 \mathrm{~mm} ;+++=>20 \mathrm{~mm}$.

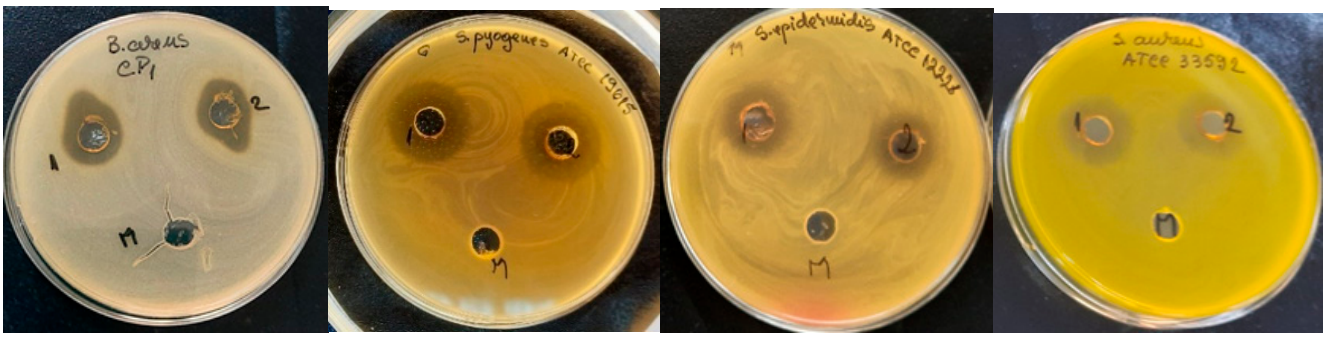

Figure 1. Visual aspects of inhibitory activity of the formula based on A. millefolium, O. vulgare, and L. coronaria on different pathogenic bacteria. From left to right: B. cereus, S. pyogenes, S. epidermidis, and S. aureus. 1 and 2 represent the duplicate of the developed formula.

Regarding antifungal activity, no inhibition was observed against any of the tested Candida and Aspergillus species.

The results indicate that the formula could be a candidate as an active ingredient of cosmetic products protecting the skin from the harmful impact of environmental factors. It is widely recognized that, in this area, plant extracts can act in two ways: by reducing skin infections and also by inhibiting the growth of microorganisms inside cosmetic products [25].

Among microorganisms causing skin infections, Staphylococcus aureus is one of the most widespread, and it is also partially responsible for atopic dermatitis (AD) symptoms [26]; superficial, but also deep, ulcerative skin infections; infection of hair follicles; abscesses; wounds; and ulcers [27]. Moreover, P. aeruginosa, S. aureus, and C. albicans are considered the main potential pathogens in cosmetic products.

The inhibitory potential of our formula should be approached as a combined, cumulative activity of the antimicrobial active substances of all three plants. Different authors have reported microbial inhibition for two out of the three used plants (A. millefolium and O. vulgare). Among the three plant species included in the formula, A. millefolium was reported to be one of the most common medicinal plants used in the Balkan area for its antimicrobial activity [28]. Some studies are coming in support. Ethanolic extract of Achillea species showed a broad spectrum of strong antibacterial activities against K. pneumoniae, 
E. cloacae, S. typhimurium, S. epidermis, E. coli, E. aerogenes, S. aureus, Klebsiella oxytoca, S. pyogenes, P. aeruginosa, and C. albicans [29].

Romer et al. [30], evidenced the fact that tincture of A. millefolium has significant inhibitory activity on Staphylococcus aureus, but not on E. coli or P. aeruginosa. A higher inhibition spectrum was exhibited by A. millefolium and its hybrid Achillea collina, Becker essential oils against E. coli, Shigella flexneri, Klebsiella pneumoniae, Salmonella typhimurium and Staphylococcus aureus, but no activity was noted against Clostridium perfringens or Streptococcus pyogenes [31,32]. It was suggested that the inhibitory effects could be attributed to the major constituents of the essential oils, respectively, caryophyllene, chamazulene, and $\beta$-pinene, and also of the minor components with strong antimicrobial activity, such as 1,8-cineole, limonene, or $\alpha$-pinene [32]. Meanwhile, ethanolic extracts of the aerial parts of O. vulgare were proven to have some antibacterial activity on Listeria monocytogenes and Staphylococcus aureus, as well as antifungal activity on Candida albicans [33]. Our formula did not show any anti-Candida activity. O. vulgare essential oil (EO) contains high amounts of thymol and carvacrol, compounds known for their excellent antimicrobial activity alone or in combination with other antibiotics [9]. This may be a reason why different extracts of O. vulgare exhibit inhibitory activity against E. coli, S. aureus, C. albicans, and P. aeruginosa [9]. The species $L$. coronaria was not so often reported for its antimicrobial activity. However, it was proven that methanol and ethanol extracts of Lychnis flos-cuculi, from the same genus, inhibit the growth of microorganisms-both Gram-negative and Gram-positive bacteria [34]. It is known from the literature that slightly polar acylated ecdysteroids from Lychnis possess antimicrobial activity [35].

\section{Conclusions}

A formula made of Achillea millefolium, Origanum vulgare, and Lychnis coronaria was biochemically characterized and tested for its antimicrobial and nonirritant activity. Important content levels of polyphenols, triterpenes, and polyphenol carboxylic acids were found in the mixture, as a cumulative result of each plant compound. The formula proved to have high antioxidant potential. Regarding antimicrobial activity, the product showed inhibitory activity on both Gram-positive and Gram-negative bacteria, respectively, moderate inhibition on B. cereus, Kocuria kristinae, P. aeurginosa, S. enterica Typhimurium, and methicillin-resistant and methicillin-sensible $S$. aureus, as well as high inhibition on S. epidermidis, Serratia marescens, and Streptococcus pyogenes. No inhibitory activity was noticed in the case of Candida spp. and Aspergillus spp. The proven nonirritant action of the product supports its potential use in pharmaco-cosmetic products. Furthermore, we expect the development of a new cosmetic formula, based on this plant extract mixture, to be used for different skin infections associated with the presence of the staphylococci, such as acne.

Author Contributions: Conceptualization, A.G.; technological studies, L.C.P.; chemical analysis, I.B.; in vitro studies, G.N.; microbiology assays, C.F.D.; validation, L.G.; formal analysis, C.I.; supervision, F.M. All authors have read and agreed to the published version of the manuscript.

Funding: This research was supported by The Executive Unit for Financing Higher Education, Research, Development and Innovation (UEFISCDI) in the frame of the project 22PTE/2020.

Institutional Review Board Statement: Not applicable.

Informed Consent Statement: Not applicable.

Conflicts of Interest: The authors declare no conflict of interest.

\section{References}

1. Mazzei, R.; Leonti, M.; Spadafora, S.; Patitucci, A.; Tagarelli, G. A review of the antimicrobial potential of herbal drugs used in popular Italian medicine (1850s-1950s) to treat bacterial skin diseases. J. Ethnopharmacol. 2020, 250, 112443. [CrossRef] [PubMed]

2. Guglielmi, P.; Pontecorvi, V.; Rotondi, G. Natural compounds and extracts as novel antimicrobial agents. Expert Opin. Ther. Pat. 2020, 30, 949-962. [CrossRef] 
3. Ayaz, M.; Ullah, F.; Sadiq, A.; Ullah, F.; Ovais, M.; Ahmed, J.; Devkota, H.P. Synergistic interactions of phytochemicals with antimicrobial agents: Potential strategy to counteract drug resistance. Chem. Biol. Interact. 2019, 308, 294-303. [CrossRef]

4. $\quad$ Enioutina, E.Y.; Teng, L.; Fateeva, T.V.; Brown, J.C.S.; Job, K.M.; Bortnikova, V.V.; Krepkova, L.V.; Gubarev, M.I.; Sherwin, C.M.T. Phytotherapy as an alternative to conventional antimicrobials: Combating microbial resistance. Expert Rev. Clin. Pharmacol. 2017, 10, 1203-1214. [CrossRef] [PubMed]

5. Pisoschi, A.M.; Pop, A.; Georgescu, C.; Turcuş, V.; Olah, N.K.; Mathe, E. An overview of natural antimicrobials role in food. Eur. J. Med. Chem. 2018, 143, 922-935. [CrossRef]

6. Amparo, T.R.; Seibert, J.B.; Vieira, P.M.A.; Teixeira, L.F.M.; Santos, O.D.H.D.; de Souza, G.H.B. Herbal medicines to the treatment of skin and soft tissue infections: Advantages of the multi-targets action. Phytother. Res. 2020, 34, 94-103. [CrossRef]

7. Verkaik, M.J.; Busscher, H.J.; Jager, D.; Slomp, A.M.; Abbas, F.; van der Mei, H.C. Efficacy of natural antimicrobials in toothpaste formulations against oral biofilms in vitro. J. Dent. 2011, 39, 218-224. [CrossRef]

8. Zhongpeng, Y.; Ling, Z. Advance in herbal medicine applied to intracanal antisepsis. Hua Xi Kou Qiang Yi Xue Za Zhi 2014, 32, 621-624.

9. Soltani, S.; Shakeri, A.; Iranshahi, M.; Boozari, M. A Review of the Phytochemistry and Antimicrobial Properties of Origanum vulgare L. and Subspecies. Iran. J. Pharm. Res. 2021, 20, 268-285. [PubMed]

10. Kolodziej, H. Aqueous ethanolic extract of the roots of Pelargonium sidoides-New scientific evidence for an old anti-infective phytopharmaceutical. Planta Med. 2008, 74, 661-666. [CrossRef]

11. Salehi, B.; Selamoglu, Z.; Sevindik, M.; Fahmy, N.M.; Al-Sayed, E.; El-Shazly, M.; Csupor-Löffler, B.; Yazdi, S.E.; Sharifi-Rad, J.; Arserim-Uçar, D.K.; et al. Achillea spp.: A comprehensive review on its ethnobotany, phytochemistry, phytopharmacology and industrial applications. Cell. Mol. Biol. 2020, 66, 78-103. [CrossRef]

12. Radusiene, J.; Gudaityte, O. Distribution of proazulenes in Achillea millefoliums wild populations in relation to phytosociological dependence and morphological characters. Plant Genet. Resour. 2005, 3, 136-143. [CrossRef]

13. Strzępek-Gomółka, M.; Gaweł-Bęben, K.; Kukula-Koch, W. Achillea Species as Sources of Active Phytochemicals for Dermatological and Cosmetic Applications. Oxid. Med. Cell. Longev. 2021, 2021, 6643827. [CrossRef]

14. Zengin, G.; Aktumsek, A.; Ceylan, R.; Uysal, S.; Mocan, A.; Guler, G.O.; Mahomoodally, M.F.; Glamočlija, J.; Ćirić, A.; Soković, M.; et al. Shedding light on the biological and chemical fingerprints of three Achillea species (A. biebersteinii, A. millefolium and A. teretifolia). Food Funct. 2017, 8, 1152-1165. [CrossRef] [PubMed]

15. Anonymus. The Wealth of India, Publication $\mathcal{E}$ Information Directorate; Council of Scientific and Industrial Research: New Delhi, India, 1962; p. 186.

16. Güvensen, N.C.; Keskin, D.; Yildiz, K. Comparision of antimicrobial activity of different extracts of Silene coronaria (Desr.) Clairv. ex Rchb. and Silene denizliensis Aytaç. grown in Turkey. Glob. J. Res. Med. Plants Indig. Med. 2016, 5, $286-291$.

17. Ai-Turki, A.I.; Ei-Ziney, M.G.; Abdel-Salam, A.M. Chemical and anti-bacterial characterization of aqueous extracts of oregano, marjoram, sage and licorice and their application in milk and labneh. J. Food Agric. Environ. 2008, 6, 39-44.

18. Babacan, O.; Cengiz, S.; Akan, M. Detection of antibacterial effect of oregano plant on various Salmonella serotypes. Ank. Univ. Vet. Fak. Derg. 2012, 59, 103-106.

19. Brand-Williams, W.; Cuvelier, M.E.; Berset, C. Use of a free radical method to evaluate antioxidant activity. LWT Food Sci. Technol. 1995, 28, 25-30. [CrossRef]

20. Oniga, I.; Pușcaș, C.; Silaghi-Dumitrescu, R.; Olah, N.K.; Sevastre, B.; Marica, R.; Marcus, I.; Sevastre-Berghian, A.C.; Benedec, D.; Pop, C.E.; et al. Origanum vulgare ssp. vulgare: Chemical Composition and Biological Studies. Molecules 2018, 23, 2077. [CrossRef] [PubMed]

21. Apel, L.; Lorenz, P.; Urban, S.; Sauer, S.; Spring, O.; Stintzing, F.C.; Kammerer, D.R. Phytochemical characterization of different yarrow species (Achillea sp.) and investigations into their antimicrobial activity. Z. Naturforsch C J. Biosci. 2020, 76, 55-65. [CrossRef]

22. Benedec, D.; Hanganu, D.; Oniga, I.; Filip, L.; Bischin, C.; Silaghi-Dumitrescu, R.; Tiperciuc, B.; Vlase, L. Achillea schurii Flowers: Chemical, Antioxidant, and Antimicrobial Investigations. Molecules 2016, 21, 1050. [CrossRef] [PubMed]

23. Ferry, S.; Darbour, N. Phenolic acids of three species of Lychnis: Lychnis alba Mill., Lychnis flos-cuculi L.; Lychnis githago Scop. Plant. Med. Phytother. 1979, 13, 192-198.

24. Guz, L.; Adaszek, Ł.; Wawrzykowski, J.; Ziętek, J.; Winiarczyk, S. In vitro antioxidant and antibabesial activities of the extracts of Achillea millefolium. Pol. J. Vet. Sci. 2019, 22, 369-376.

25. Halla, N.; Fernandes, I.P.; Heleno, S.A.; Costa, P.; Boucherit-Otmani, Z.; Boucherit, K.; Rodrigues, A.E.; Ferreira, I.C.; Barreiro, M.F. Cosmetics Preservation: A Review on Present Strategies. Molecules 2018, 23, 1571. [CrossRef]

26. Di Domenico, E.G.; Cavallo, I.; Capitanio, B.; Ascenzioni, F.; Pimpinelli, F.; Morrone, A.; Ensoli, F. Staphylococcus aureus and the Cutaneous Microbiota Biofilms in the Pathogenesis of Atopic Dermatitis. Microorganisms 2019, 7, 301. [CrossRef]

27. Liu, Q.; Mazhar, M.; Miller, L.S. Immune and Inflammatory Reponses to Staphylococcus aureus Skin Infections. Curr. Dermatol. Rep. 2018, 7, 338-349. [CrossRef] [PubMed]

28. Purcaru, T.; Diguta, C.F.; Matei, F. Antimicrobial potential of Romanian spontaneous flora-A minireview. Sci. Pap. Ser. B Hortic. 2018, LXII, 667-680.

29. Baris, D.; Kizil, M.; Aytekin, C.; Kizil, G.; Yavuz, M.; Ceken, B.; Ertekin, A.S. In vitro antimicrobial and antioxidant activity of ethanol extract of three Hypericum and three Achillea species from Turkey. Int. J. Food Prop. 2011, 14, 339-355. [CrossRef] 
30. Romero, C.D.; Chopin, S.F.; Buck, G.; Martinez, E.; Garcia, M.; Bixby, L. Antibacterial properties of common herbal remedies of the southwest. J. Ethnopharm. 2005, 99, 253-257. [CrossRef]

31. Jianu, C.; Mişcă, C.; Muntean, S.G.; Gruia, A.T. Composition, antioxidant and antimicrobial activity of the essential oil of Achillea collina Becker growing wild in western Romania. Hem. Ind. 2015, 69, 381-386. [CrossRef]

32. Jianu, C.; Golet, I.; Misca, C.; Jianu, A.M.; Pop, G.; Gruia, A.T. Antimicrobial properties and chemical composition of essential oils isolated from six medicinal plants grown in Romania against foodborne pathogens. Rev. Chim. 2016, 67, $1056-1061$.

33. Benedec, D.; Hanganu, D.; Oniga, I.; Tiperciuc, B.; Olah, N.K.; Raita, O.; Bischin, C.; Silaghi-Dumitrescu, R.; Vlase, L. Assessment of rosmarinic acid content in six Lamiaceae species extracts and their antioxidant and antimicrobial potential. Pak. J. Pharm. Sci. 2015, 28, 2297-2303. [PubMed]

34. Maliński, M.P.; Michalska, A.D.; Tomczykowa, M.; Tomczyk, M.; Thiem, B. Ragged Robin (Lychnis flos-cuculi)—A plant with potential medicinal value. Rev. Bras. Farmacog. 2014, 24, 722-730. [CrossRef]

35. Mamadalieva, N.Z. Phytoecdysteroids from Silene plants: Distribution, diversity and biological (antitumour, antibacterial and antioxidant) activities. Bol. Latinoam. Caribe. Plant Med. Aromat. 2012, 11, 474-497. 